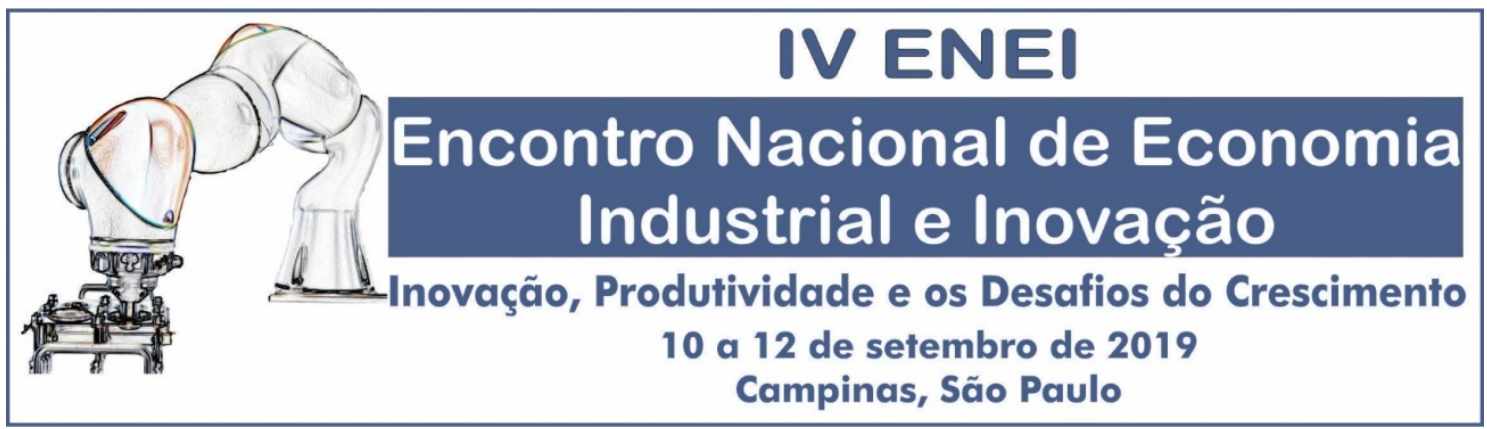

\title{
PARTICIPAÇÃO DOS PAÍSES EM DESENVOLVIMENTO NAS CADEIAS GLOBAIS DE VALOR E DEPENDÊNCIA TECNOLÓGICA - UMA ANÁLISE EMPÍRICA DE COMÉRCIO E DE RENDA DE PROPRIEDADE INTELECTUAL
}

Ludmila Macedo Corrêa - Departamento de Ciências Econômicas e Exatas da UFRRJ Eduardo Costa Pinto - Instituto de economia da UFRJ Marta dos Reis Castilho - Instituto de economia da UFRJ 


\section{PARTICIPAÇÃO DOS PAÍSES EM DESENVOLVIMENTO NAS CADEIAS \\ GLOBAIS DE VALOR E DEPENDÊNCIA TECNOLÓGICA - UMA ANÁLISE EMPÍRICA DE COMÉRCIO E DE RENDA DE PROPRIEDADE INTELECTUAL}

\section{RESUMO}

Ludmila Macedo Corrêa ${ }^{1}$ Eduardo Costa Pinto ${ }^{2}$ Marta dos Reis Castilho ${ }^{3}$

Este artigo visa analisar se a participação dos países em desenvolvimento nas Cadeias Globais de Valor (CGV) foi acompanhada de maior dependência tecnológica via renda de pagamento pelo uso de propriedade tecnológica, e se existem padrões de especialização nas cadeias específicos em que isso seja amenizado. A análise foi feita com 41 países entre 1995 e 2011, utilizando-se cinco indicadores que captaram características inerentes ao processo. Diante da quantidade de informação, utilizou-se a técnica de clusters, permitindo identificar que independente do padrão de especialização, a maior participação dos países nas cadeias foi acompanhada de maior dependência tecnológica dos países em desenvolvimento em relação aos países desenvolvidos. Esse resultado converge com a discussão referente à propagação das CGV simultaneamente à consolidação de uma institucionalidade internacional de proteção a propriedade intelectual, que ao ampliar as posições monopolistas das grandes corporações, sediadas geralmente nos países desenvolvidos, acentua as assimetrias tecnológicas existentes entre os países.

Palavras chave: Cadeias Globais de Valor, upgrading, pagamento pelo uso de propriedade intelectual, análise de cluster.

JEL: F23, L23, O14, O34.

Área temática: 2. Comércio internacional, cadeias de valor e internacionalização

\section{PARTICIPATION OF DEVELOPING COUNTRIES IN THE GLOBAL VALUE AND TECHNOLOGICAL DEPENDENCE CHAINS - AN EMPIRICAL ANALYSIS OF TRADE AND INTELLECTUAL PROPERTY INCOME}

\section{ABSTRACT}

This paper aims at analyzing whether the participation of developing countries in Global Value Chains (CGV) was accompanied by a greater technological dependence via payment income for the use of technological property, and if there are specific patterns of specialization in the chains where this is mitigated. The analysis was done with 41 countries between 1995 and 2011, using five indicators that captured characteristics inherent to the process. Given the amount of information, the clusters technique was used, allowing to identify that, regardless of the standard of specialization, the greater participation of the countries in the chains was accompanied by a greater technological dependence of the developing countries on the developed countries. This result converges with the discussion concerning the spread of the CGVs simultaneously with the consolidation of an international institutional framework for the protection of intellectual property, which, by broadening the monopolistic positions of large corporations, usually based in developed countries, accentuates the technological asymmetries existing between countries.

Key words: Global Value Chains, upgrading, payment for use of intellectual property, cluster analysis

1. Professora do Departamento de Ciências Econômicas e Exatas da UFRRJ

2. e 3. Professores do Instituto de economia da UFRJ 


\section{PARTICIPAÇÃO DOS PAÍSES EM DESENVOLVIMENTO NAS CADEIAS \\ GLOBAIS DE VALOR E DEPENDÊNCIA TECNOLÓGICA - UMA ANÁLISE EMPÍRICA DE COMÉRCIO E DE RENDA DE PROPRIEDADE INTELECTUAL}

\section{INTRODUÇÃO}

A fragmentação internacional da produção e formação das Cadeias Globais de Valor (CGV) tem se expandido significantemente nas últimas duas décadas, alterando a configuração mundial da produção e do comércio. Diversas atividades da cadeia de valor desempenhadas por firmas líderes, geralmente originárias de países desenvolvidos, passaram a ser terceirizadas e desempenhadas por firmas contratadas sediadas geralmente nos países em desenvolvimento.

Este novo paradigma de organização da produção vem abrindo diferentes possibilidades de inserção dos países em desenvolvimento nas cadeias globais, gerando também diferentes resultados sobre suas economias. Identifica-se, em geral, a participação nas cadeias contribuindo para o crescimento do produto e exportações dos países envolvidos, e ainda para alguns, mudanças mais expressivas como diversificação e sofisticação da composição de grande parte de suas estruturas produtivas. Esses diferentes resultados associam-se ao padrão de especialização dos países definido pela atividade desempenhada na cadeia (etapa de atuação) e o efeito de transbordamento desta atividade sobre o restante da economia. Esse padrão pode ser o mesmo desde o momento da inserção ou então passar por sofisticações ao longo do tempo através de upgradings.

A sofisticação na composição do comércio e da estrutura produtiva dos países obtida a partir deste paradigma produtivo apresenta especificidades quanto ao potencial em transbordar para o restante da economia. Os países em desenvolvimento que se insere nas CGV sofisticam-se tecnologicamente utilizando tecnologia ou conhecimento mais avançados desenvolvidos no exterior (países desenvolvidos), mas por serem protegidos por direitos de propriedade intelectual, dificultam o enraizamento local dessa tecnologia e a capacidade do país em adaptá-la e desenvolvê-la.

Assim, a consolidação e propagação de um sistema internacional de direito de propriedade ao dificultar o processo de endogenização tecnológica, garante o poder de comando das empresas líderes na distribuição da captura de valor adicionado (VA) entre os países participantes, dificultando-se o upgrading dos países em desenvolvimento nas mesmas, caso isto represente perda de captura de VA pelas empresas líderes.

Como resultado da participação nessas CGV, os países em desenvolvimento, em geral, apresentam por um lado, variações positivas no saldo da balança comercial decorrente de sua maior inserção (acompanhado frequentemente por sofisticação da pauta exportadora), mas, por outro lado, remetem fluxos crescentes de renda de pagamento pelo uso de propriedade intelectual em função da proteção da tecnologia ou da marca utilizada, acentuando ainda mais seus déficits recorrentes na balança de serviço. Esses fatos combinados sugerem um aumento da dependência tecnológica desses países em relação aos países desenvolvidos via aumento das despesas com pagamento pelo uso de propriedade intelectual, com grandes obstáculos a reversão desse cenário em função de uma institucionalidade internacional criada que consolida a atual divisão do poder e captura de valor adicionado entre os agentes ou mesmo, entre os países.

Diante dos efeitos nas diferentes dimensões econômicas ressaltadas, este artigo tem como objetivo analisar empiricamente se a participação dos países em desenvolvimento nas Cadeias Globais de Valor (CGV) veio acompanhada de maior dependência tecnológica em relação aos países desenvolvidos via renda de pagamento pelo uso de propriedade tecnológica e se existem padrões de especialização nas cadeias específicos em que isso seja amenizado.

A análise foi feita com uma amostra de 41 países no período entre 1995 e 2011 utilizando-se cinco indicadores: índice de participação (IP); valor adicionado doméstico nas exportações (DVA); valor adicionado doméstico de serviços sofisticados nas exportações (VAXserv); exportação de manufaturas intensivas em tecnologia (ExpHT) e padrões da variação dos saldos de pagamento pelo uso de propriedade intelectual e da balança comercial (PIntelec_BC). Esses indicadores analisados em conjunto irão captar características do padrão de especialização nas $\mathrm{CGV}$ simultaneamente ao 
comportamento de variáveis de propriedade intelectual. Diante da quantidade de informação disponível, optou-se pela análise simultânea dos indicadores via técnica de cluster, cuja metodologia identificou padrões entre participação nas cadeias de valor e dependência tecnológica.

A análise empírica da participação dos países nas CGV considerando os efeitos do paradigma produtivo sobre a capacidade tecnológica dos países se mostra pioneira na literatura atual, num cenário em que o assunto é analisado, em geral, no âmbito do comércio com base em estatísticas tradicionais ou em termos de valor adicionado. Além disso, o trabalho contribui para preencher a lacuna existente nas análises empíricas quanto aos ganhos superiores obtidos pelos países desenvolvidos, que ao terceirizarem somente as atividades de baixa criação de valor adicionado, são os que ficam com a maior parcela da captura dos ganhos da cadeia produtiva, no entanto, cujos ganhos não são captados pelos dados de comércio.

\section{Participação dos países nas CGV, padrões de especialização e dependência tecnológica - efeitos sobre comércio e renda de propriedade intelectual.}

Essa seção visa apresentar características gerais das CGV e os padrões de especialização dos países, em especial dos países em desenvolvimento, discutindo-se também como estes podem provocar mudanças nos fluxos e composição do comércio, mas também na dependência tecnológica dos países, avaliada através dos fluxos de renda pelo uso de propriedade intelectual.

\section{a. Cadeias globais de valor: padrões de especialização e ganhos decorrentes}

O processo de fragmentação internacional da produção e a formação das CGV vêm expandindo-se significantemente nas últimas décadas como estratégia de internacionalização das grandes corporações, que identificaram nesse padrão organizacional uma forma de ampliar eficiência produtiva e rentabilidade num cenário de maior concorrência sob novas circunstâncias internacionais referente à liberalização e desregulamentação dos mercados.

O fatiamento e distribuição da cadeia produtiva de processos produtivos descontínuos em diferentes regiões imprimiram novas características à divisão internacional do trabalho, conduzindo a uma reorganização da produção e do comércio em torno de redes globais/ regionais e reposicionando os países em desenvolvimento no cenário internacional (SARTI \& HIRATUKA, 2010; BALDWIN, 2012; MILBERG \& WINKLER, 2013).

A fragmentação do processo produtivo dos bens faz com que a localização das etapas nas diferentes regiões fique condicionada às vantagens comparativas "caleidoscópicas" diversos países. Esta mudança decorre do fato de que as diferentes etapas do processo produtivo geram diferentes níveis de agregação de valor, e que a possibilidade de separá-las, permite que os países se concentrem em capturar valor adicionado (VA) em etapas específicas. De acordo com Baldwin (2012), as etapas que geram maior VA são os estágios pré e pós-fabricação, formados basicamente por serviços - concepção, design, $P \& D$, vendas, marketing e serviços pós-venda - cujos potenciais de criação de VA das atividades são relacionados na "smile curve".

Diante dos diferenciais de captura de VA entre as atividades de uma cadeia produtiva, observam-se os países em desenvolvimento atuando frequentemente como fornecedores de matériasprimas ou em atividades de processamento e montagem de produto final, enquanto os países desenvolvidos vêm aumentando sua participação em atividades de maior VA como produção de peças e componentes de alta tecnologia ou mesmo restringindo-se a segmentos de serviços como atividades de criação do produto - design e P\&D (MEMEDOVIC \& IAPADRE, 2009). Em algumas situações, observa-se também a distribuição geográfica de algumas atividades sofisticadas, que apesar de se concentrarem principalmente nos países desenvolvidos, os países em desenvolvimento vêm conquistando espaços maiores nestas atividades. Tal inserção não ocorre de forma homogênea, com o desempenho deste grupo fortemente associado ao desenvolvimento de competências tecnológicas em

1 Vantagens em cada etapa do processo produtivo, em oposição às vantagens comparativas em termos de bens finais da teoria tradicional (MEMEDOVIC \& IAPADRE, 2009). 
determinadas áreas de conhecimento, o que os permitem captar investimentos estrangeiros em atividades mais nobres (MIRANDA, 2014).

A reconfiguração espacial das etapas de produção entre os países decorre de novos formatos de governança das firmas que compõem as CGV - cujo padrão depende de suas posições hierárquicas nas cadeias e que determina o potencial de captura do VA de cada uma dessas firmas.

Nesta lógica, identificam-se dois agentes: $i$.) firmas líderes - presentes predominantemente nos países desenvolvidos - detentoras do controle sobre a tecnologia, $\mathrm{P} \& \mathrm{D}$, propriedade intelectual e marcas e que capturam a maior parte do $\mathrm{VA}^{2}$; e ii.) empresas contratadas pelas firmas líderes sediadas em países em desenvolvimento - realizando em geral etapas manufatureiras de baixo VA ou mesmo serviços pouco intensivos em conhecimento, ou então com estes totalmente protegidos por direitos de propriedade (PINTO et.al, 2015; STURGEON \& GEREFFI, 2013).

Em termos gerais, afirma-se que a descentralização da cadeia de produção ocorre de forma hierárquica e seletiva (SARTI \& HIRATUKA, 2010). Hierárquica em virtude da maior parcela do valor adicionado do processo produtivo permanecer, em geral, na matriz destas corporações (firmas líderes) sendo terceirizadas principalmente as atividades de baixo VA. E seletiva, pois essa hierarquia na distribuição do VA também ocorre entre os países. As etapas terceirizadas por serem, com frequência, intensivas em trabalho ou recursos naturais, são deslocadas para países em desenvolvimento, abundantes em tais fatores (por meio de firmas contratadas). Ressalta-se ainda que quando houver internacionalização das atividades tecnológicas, estas preservam o caráter hierárquico e seletivo da mesma forma que na esfera produtiva. As firmas líderes mantêm o controle da distribuição das atividades e estas vão somente para os países que apresentam alguma vantagem tecnológica ou de conhecimento para desenvolvê-las (MIRANDA, 2014).

Diante desse padrão de descentralização da cadeia em paralelo ao controle pelas grandes corporações do restante das firmas envolvidas (firmas fornecedoras/contratadas) no que diz respeito à natureza dos contratos e transferência de tecnologia, a descentralização ocorre simultaneamente à maior concentração do poder de comando sobre a criação de VA nas cadeias. Milberg e Winkler (2013) defendem ainda que a manutenção da captura assimétrica de VA entre as partes envolvidas é endógena as estratégias das corporações, evidenciando a resistência ou impedimento a qualquer alteração de posição dos países em desenvolvimento na atuação nessas cadeias de valor.

No lado das empresas contratadas, sediadas em geral nos países em desenvolvimento, identifica-se que a atração de etapas produtivas intensivas em mão-de-obra dos países centrais (e em alguns casos, etapas mais sofisticadas) contribui para a obtenção de ganhos pelos primeiros, ainda que essa dinâmica seja moldada pelos interesses das empresas líderes.

Assim, a inserção desses países nas CGV pode contribuir para a geração de emprego, renda e aumento das exportações, possibilitando em muitos casos, na sofisticação da composição dessas exportações. Anteriormente, esses países caracterizavam-se por serem exportadores de produtos primários, mas com a fragmentação internacional da produção, suas pautas exportadoras passaram a apresentar peso significativo das manufaturas, inclusive, as intensivas em tecnologia, sendo que em alguns casos, uma maior expressividade de serviços sofisticados.

Diante disso, observa-se a participação nessas redes internacionais de produção representando para muitos, um avanço em termos de industrialização, que reflete no curto prazo em um aumento das exportações, do emprego e da renda (UNCTAD, 2013; MEMEDOVIC e IAPADRE, 2009). Dentre esses países, identifica-se ainda que para alguns, os ganhos se estenderam para o longo prazo, com a maior atuação em segmentos industriais mais sofisticados ou de atividades de serviços intensivas em conhecimento, gerando efeitos de transbordamento para outros setores e com reflexos positivos sobre a produtividade média (UNIDO, 2013).

Para aqueles com ganhos restritos ao curto prazo, a alteração do padrão de especialização da economia influenciado pela inserção nas cadeias pode limitar-se ao setor exportador, com poucos efeitos de encadeamento sobre a economia. Neste caso, a sofisticação da pauta exportadora não reflete na melhora da estrutura produtiva do país, podendo caracterizar um aprisionamento do país em

\footnotetext{
2 Em algumas situações, a escala de produção será o ativo específico.
} 
atividades de pouco VA. A baixa endogenização tecnológica dessa atividade e o limitado dinamismo econômico decorrente refletirão no lock-in do país em sua estrutura de produção.

Assim, constata-se que os diferentes potenciais de ganhos obtidos com as CGV têm relação com o padrão de especialização dos países nas cadeias que se associa à etapa de atuação dentro da cadeia produtiva (atividade desempenhada) e o efeito de transbordamento desta atividade sobre o restante da economia (via encadeamento e/ou potencial de learning da atividade). Esses transbordamentos podem incentivar a uma atuação em atividades intensivas em conhecimento e/ou em cadeias de valor mais sofisticadas, com efeitos positivos sobre a composição de sua estrutura produtiva e do nível de produtividade, representando um ganho de longo prazo.

Os padrões de especialização dos países nas cadeias podem ser o mesmo desde o momento da inserção ou então passar por sofisticações ao longo do tempo através de upgradings $^{3}$. Em alguns países, a participação nas cadeias restringe-se a atividade desempenhada durante a inserção, enquanto em outros, observa-se uma participação mais abrangente, com avanço destes em termos de: $i$ ) maior eficiência de seus processos produtivos (upgrading de processo); ou ii) melhores produtos produzidos (upgrading de produto);ou iii) direcionamento para cadeias de valor mais sofisticadas (upgrading de cadeia); e/ou iv) de atividade desempenhada em termos de intensidade de conhecimento (upgrading funcional). As diferentes formas de participação nas cadeias (inserção e upgrading) influenciam o padrão de especialização dos países refletindo também nos diferentes resultados (MILBERG e WINKLER, 2013; UNCTAD, 2013, HUMPHREY e SCHMITZ, 2002).

Com o upgrading de produto e/ou processo, pode haver um fortalecimento da posição do país nas cadeias, em que com o apoio da firma líder (maior retorno para elas), consegue-se ter ganhos de curto prazo referente à exportação, produto e emprego, sem, no entanto, ser suficiente para alteração de sua estrutura produtiva. Já o upgrading de cadeia e/ou funcional - em função do efeito de transbordamento de cadeias ou atividades mais sofisticadas - potencializa os ganhos da participação, tendendo a impactar positivamente sobre a composição de suas estruturas de produção. O upgrading funcional, apesar de desestimulado pelas empresas líderes por temer perder espaço na captura de VA nas cadeias, é positivo para os países que o realizam pelo seu potencial em sustentar ganhos da participação nas cadeias ao longo do tempo. Exercer atividades que empregam predominantemente mão-de-obra qualificada permite que suas posições não fiquem vulneráveis à inserção de economias mais atrasadas, atuantes em atividades intensivas em trabalho não-qualificado e com baixos salários (MILBERG \& WINKLER, 2013).

Como já destacado, os diferentes potencias de ganhos da participação nas CGV associam-se ao padrão de especialização do país nas cadeias quanto à intensidade tecnológica ou em conhecimento dessa participação, seja setorial ou de atividade desenvolvida. E, caso essa participação não envolva os aspectos citados, ressaltou-se a possibilidade de evolução nesse padrão via upgrading de cadeia ou funcional, e com isso, evitando o aprisionamento em setores ou atividades de baixo potencial de criação de valor adicionado.

No entanto, ressalta-se que a evolução ao longo da cadeia não é automática. A simples participação não é suficiente para o país obter ganhos inerentes a essa evolução. Observa-se um desinteresse das firmas líderes e até imposição de obstáculos aos países em desenvolvimento para avançarem no padrão de atuação. Assim, são necessários esforços específicos nesses países em termos de política econômica voltados ao processo de endogenização tecnológica cuja discussão foge do escopo do presente artigo (STURGEON e MEMEDOVIC, 2010, ERNEST e KIM, 2002).

\section{b. Cadeias Globais de Valor e dependência tecnológica - uma análise de fluxo de renda de pagamento pelo uso de propriedade intelectual}

A propagação e difusão das CGV vieram acompanhadas da defesa e da imposição de um sistema internacional de propriedade intelectual pelos países desenvolvidos, com destaque o papel

\footnotetext{
${ }^{3}$ Upgrading econômico como mecanismo de superação do padrão de especialização ditado pelas vantagens comparativas via movimentos ao longo da cadeia em busca de maior captura de VA (MILBERG \& WINKLER, 2013).
} 
assumido pelos Estados Unidos no âmbito da OMC. Isso ocorre via exigência de um padrão mínimo de proteção intelectual aos países membros da organização, que devem abdicar ou adequar seus sistemas nacionais ao padrão internacional determinado pelo Trade Related Intelectual Property System -TRIPS (PINTO et.al., 2015; DURAND \& MILBERG, 2018). Com isso, as empresas transnacionais - sediadas, em geral, nos países desenvolvidos e que lideram o processo de fragmentação internacional da produção - asseguram o controle de marcas, segredos industriais e conhecimento, simultaneamente a terceirização de etapas produtivas e o consequente "empréstimo de tecnologia". Este consiste em disponibilizar especificamente a tecnologia e/ou conhecimento utilizados na atividade, altamente protegidos e sem possibilidade de sua decodificação e enraizamento local (BALDWIN, 2012).

Além da apropriação dos royalties de patentes e marcas, esse sistema de propriedade intelectual assegura o poder de comando das empresas que possuem posições dominantes nas cadeias e que determina a distribuição de captura de VA entre os participantes. Neste caso, o sistema de propriedade intelectual garante o padrão de governança na cadeia de valor, impedindo ou dificultando o upgrading dos países em desenvolvimento nas mesmas, caso isto represente perda de captura de VA pelas empresas líderes (PINTO et. al., 2015). A garantia da propriedade intelectual assegura o poder de monopólio dessas firmas, classificado como um monopólio intelectual, cujo poder decorre da criação de ativos intangíveis (DURAND \& MILBERG, 2018; PAGANO'S, 2014; MEDEIROS \& TREBAT,2017). Assim, segundo Miranda (2014), a atuação das grandes corporações nesse paradigma produtivo - e o próprio processo de internacionalização da tecnologia inerente - estaria contribuindo não para uma convergência tecnológica, mas para consolidar as assimetrias entre os países.

Numa linha similar, mas não abordando diretamente as CGV, Carlotto e Pinto (2015) defendem o estabelecimento de um padrão internacional de propriedade intelectual que beneficia diretamente os interesses comerciais americanos e que acentua a atual divisão internacional do trabalho e o padrão assimétrico de desenvolvimento entre os países desenvolvidos e em desenvolvimento. Segundo os autores, a "diplomacia da propriedade intelectual" decorrente da imposição internacional de um padrão de propriedade intelectual, além de garantir o controle científico e tecnológico, tem compensado os déficits na balança comercial dos EUA, processo este acentuado pela transferência de etapas produtivas manufatureiras para outros países.

Assim, na discussão sobre paradigma produtivo relativo às CGV e a consolidação de um sistema internacional de propriedade intelectual, identificam-se efeitos microeconômicos, mas que transbordam para a esfera macroeconômica. O primeiro refere-se ao controle e comando de certos agentes econômicos (empresas líderes) sobre o conhecimento e tecnologia e que lhes proporcionam maior captura de VA, em oposição à maior subordinação dos agentes responsáveis por atividades não sofisticadas do processo produtivo. Sobre os efeitos macroeconômicos, como o primeiro grupo encontra-se, em geral, nos países desenvolvidos e o segundo, nos países em desenvolvimento, isso refletirá na dificuldade destes últimos avançarem nas cadeias de valor sob a forma de upgrading, e assim não obtendo, ou então de forma limitada, os efeitos de longo prazo dessa atuação.

A performance obtida em cada uma desses grupos de países reflete na composição da conta corrente de seus balanços de pagamentos. Os participantes de etapas produtivas finais de montagem recebem o "título" de exportadores de bens finais, afetando positivamente o saldo de suas balanças comerciais, enquanto os atuantes em etapas mais sofisticadas de criação e desenvolvimento de produtos (formação de ativos intangíveis) representam os exportadores de conhecimento, tecnologia e marca, com impacto positivo sobre suas balanças de serviço.

Nesse sentido, constatam-se a difusão das CGV e o avanço de alguns países em desenvolvimento em seus processos de industrialização a partir da participação neste paradigma produtivo, no entanto, uma superficialidade dessa industrialização limitando o aprofundamento desse processo em virtude da ampliação da dependência de tecnologia e conhecimento oriundos dos países desenvolvidos (Baldwin, 2012). Esse cenário pode refletir no aumento dos saldos negativos nos fluxos de renda de pagamento pelo uso de propriedade intelectual, que acentuam os déficits recorrentes nas balanças de serviços, e que podem não ser compensados totalmente por balanças comerciais superavitárias decorrentes da exportação de produtos manufaturados. 
Em vista da propagação do paradigma produtivo inerente as CGV e a ampla participação dos países em desenvolvimento nessas cadeias, identificam-se como importante verificar se a participação dos países em desenvolvimento nas Cadeias Globais de Valor tem sido acompanhada de maior dependência tecnológica em relação aos países desenvolvidos via renda de pagamento pelo uso de propriedade tecnológica, e se existem padrões de especialização nas cadeias específicos em que isso seja amenizado. A seguir, a descrição e justificativa dos indicadores selecionados para esta análise.

\section{INDICADORES PARA A ANÁLISE DOS PADRÕES DE ESPECIALIZAÇÃO DOS PAÍSES NAS CADEIAS: DESCRIÇÃO E JUSTIFICATIVAS}

A análise da participação dos países nas CGV é feita frequentemente por estudos de casos de países/setoriais ou então por análise agregada dos países, entretanto baseada em algum indicador específico, geralmente relacionado a comércio (UNCTAD, 2013,2018; BANGA, 2013; DE BACKER e MIRODOUT, 2013; ...). Sobre o primeiro método, Milberg \& Winkler (2013) destacam sua limitação decorrente da dificuldade de comparabilidade dos resultados em função dos distintos períodos e aspectos analisados. O segundo, por sua vez, embora permita a comparação do desempenho dos países em uma variável específica, ainda mostra-se limitado por não captar simultaneamente os efeitos das cadeias em diferentes dimensões econômicas, cujas variáveis em conjunto podem expressar determinados padrões de comportamento nas CGVs.

Em vista dessas limitações e da lacuna de análises empíricas na literatura sobre CGV envolvendo variáveis tecnológicas, optou-se por mapear os países nas CGV através de uma análise multivariada, com alguns indicadores em conjunto expressando padrões de especialização dos países nas cadeias. A realização dessa análise em paralelo ao acompanhamento do comportamento da renda de propriedade intelectual lança luz sobre a capacitação tecnológica dos países à medida que os países passam a se integrar mais às cadeias de valor. Para isto, foram considerados indicadores que captam tanto a intensidade da participação e a sofisticação dessa atuação, mas também que compare o fluxo do comércio ao fluxo de pagamento pelo uso de propriedade intelectual. Os indicadores baseiam-se em estatísticas de comércio (em termos bruto e em valor adicionado) e em dados do balanço de pagamento.

\section{a. Estatísticas de Comércio em Termos de Valor Adicionado: Bens e Serviços}

As estatísticas de comércio quando mensuradas em termos de VA estimam a origem do valor (por país e indústria) adicionado a produção voltada à exportação. Ao distinguir o VA doméstico do importado, analisa-se a influência do comércio internacional na criação de valor local e no seu potencial de criação de emprego. Essa distinção é fundamental em um cenário de fragmentação internacional da produção, dada a acentuada utilização de insumos importados na produção de bens finais. Essa estatística é calculada a partir de uma matriz insumo-produto global oriunda da harmonização de matrizes insumo produto dos países e dos coeficientes de comércio bilaterais (OECD-WTO, 2012; JOHNSON e NOGUERA, 2012).

Para um melhor entendimento, identificam-se as exportações brutas (X) formadas pelo valor adicionado doméstico incorporado nas exportações de bens e serviços (DVA) e pelo valor adicionado estrangeiro (FVA) incorporado nas exportações. No primeiro, identifica-se ainda uma parcela utilizada na demanda doméstica de outros países $\left(\mathrm{DVA}_{\mathrm{DF}}{ }^{*}\right)$ e outra incorporada nas exportações destes outros países (DVAx*). A análise do comércio nas cadeias de valor é feita com base somente no VA dos países incorporado nas exportações de terceiros (DVAx*).

Assim, a participação de um país nas CGV é mensurada considerando-se sua participação a jusante (DVAx*), como criador de VA que será embutido nas exportações de outros países, e sua participação a montante (FVA), utilizando VA importado nas suas exportações. O índice de participação (IP), equação 1, mostra a contribuição das exportações intracadeia nas exportações totais do país (KOOPMAN, WANG e WEI 2008).

$$
\mathrm{IP}=[(\mathrm{DVAx} *+\mathrm{FVA}) / \mathrm{X}]
$$


Onde: IP refere-se ao Índice de Participação nas cadeias; DVAx* ao valor adicionado doméstico contido nas exportações de terceiros, FVA ao valor adicionado estrangeiro contido nas exportações nacionais e; $\mathrm{X}$ às exportações brutas.

Como há países com participação elevada nas cadeias em 2011, entretanto, não apresentando variação significativa do Índice de Participação no período analisado, optou-se por utilizar de forma agregada o índice de participação tanto em termos de nível quanto de variação. Assim, como primeiro indicador para a análise dos diferentes padrões de especialização dos países nas Cadeias Globais de Valor, será calculado um indicador de participação nas cadeias através da média aritmética do Índice de Participação (IP) de um país em 2011 e de sua variação entre 1995 e 2011.

Indicador 1: Participação nas cadeias $=0,5 . \mathrm{IP}_{2011}+0,5 \Delta \mathrm{IP}$

Onde: "IP 2011 " refere-se ao índice de participação nas cadeias em 2011; “ $\Delta$ IP" refere-se à variação do índice de participação nas cadeias entre 95 e 2011.

O índice de participação, embora amplamente utilizado na literatura sobre as CGV, apresenta algumas limitações. O VA doméstico criado pelos países que atuam na etapa de montagem/processamento de bens finais (exportadores de bens finais) é voltado à demanda doméstica de outros países e, com isso, ignorado pelo IP (que só considera o VA doméstico incorporado nas exportações desses outros países). Neste caso, terão a participação nas cadeias contabilizada apenas via VA estrangeiro (FVA), fato este que explica o baixo IP de alguns países conhecidos como altamente integrados às cadeias ${ }^{4}$.

Outra questão de destaque sobre o indicador refere-se à preponderância da importância do componente a jusante "DVAx*" sobre o "FVA" por ser o que agrega valor localmente. Participação elevada nas cadeias decorrente de elevada importação de VA estrangeiro pode gerar problemas para o país, como situações em que se caracterizam meros "juntadores de peças" com baixa agregação de valor local. Nessa linha de priorizar o VA doméstico, Banga $(2013,2014)$ ressalta a importância do componente voltado a demanda final de outros países "DVAx ${ }_{D F}^{*}$ " mesmo para aqueles com grande participação nas cadeias.

Diante disso, optou-se por avaliar a variação do VA doméstico das exportações (DVA), cujo indicador é utilizado por diversos autores como proxy de upgrading econômico (MILBERG \& WINKLER, 2013; TAGLIONI et.al, 2016; BANGA, 2014; SMICHOWSKI et.al, 2018). Avalia-se com isso, a capacidade de criação de VA local das exportações, seja decorrente de exportações intracadeia, seja voltada à demanda doméstica de outros países, podendo estas últimas ser decorrentes de transbordamentos da primeira. Assim, será adotado como segundo indicador para a análise dos diferentes padrões de especialização dos países nas Cadeias Globais de Valor, a variação do VA doméstico nas exportações entre 1995 e 2011:

\section{Indicador 2: $\Delta$ do VA doméstico nas exportações $=\Delta(\mathrm{DVA} / \mathrm{X})$}

Onde: $\Delta$ refere-se à variação; DVA ao VA nas exportações e; X às exportações brutas.

A fragmentação do processo produtivo e a deslocalização geográfica das diferentes etapas envolveram também o setor de serviços, com muitas destas atividades executadas em terceiros países. No processo produtivo de bens existe uma série de serviços que são utilizados (transporte, comunicação, TI, financeiros e etc.) e que irão agregar valor ao produto. Ao identificar o valor criado com essas atividades, vê-se exatamente o que cada setor está produzindo, seja diretamente ou indiretamente. Em vista da maior capacidade de criação de valor adicionado de alguns serviços (smile curve) e de que as estatísticas de comércio em termos de VA permitem identificar a contribuição do setor de serviços nas exportações brutas, optou-se por estender a análise ao setor. Visa-se, com isso, identificar se a maior participação nas cadeias foi acompanhada de maior participação de serviços

4 Embora o VA doméstico nas etapas de montagem seja geralmente baixo, o montante poderá ser expressivo quando a escala de produção for elevada. 
intensivos em conhecimento e com maior capacidade de geração de VA nas exportações, representando uma sofisticação da atuação desses países nas cadeias de valor.

Assim, com base na desagregação setorial da base de dados TIVA, utilizou-se como terceiro indicador para a análise dos diferentes padrões de especialização dos países nas CGV, a variação do VA doméstico dos serviços: "financeiros"; "aluguel de maquinarias" e "serviços de negócios". Estes últimos abrangendo "computação e atividades relacionadas" e "P\&D e outras atividades de negócios relacionadas".

Indicador 3: $\Delta$ Participação do VA doméstico em serviços sofisticados nas

$$
\text { exportações }=\Delta\left(\mathrm{VAX}_{\mathrm{S} \text { a,b,c }} / \mathrm{X}\right)
$$

Onde: $\Delta$ refere-se à variação; $\operatorname{VAX}_{\mathrm{Sa}, \mathrm{b}, \mathrm{c}}$ ao valor adicionado doméstico em serviços $a, b$, e $c$ contido nas exportações, sendo (a) serviços financeiros; (b) aluguel de maquinarias e; (c) serviços de negócios; X refere-se as exportações brutas.

Para o cálculo dos indicadores desta seção, utilizou-se a base de dados OECD-WTO Trade in Value-Added (TIVA) - Maio 2015, com informações para 62 economias em 33 setores.

\section{b. Estatísticas de Comércio em Termos Brutos: Intensidade Tecnológica das Exportações}

Por a fragmentação internacional da produção ocorrer principalmente em setores intensivos em tecnologia e a participação de alguns países nas cadeias ocorrer frequentemente em atividades de processamento e montagem do produto final e isso representar uma sofisticação de suas pautas exportadoras, o presente trabalho analisará o dinamismo tecnológico das exportações a partir das estatísticas tradicionais de comércio (base de dados CONTRADE UN, nomenclatura SITC agregada em 3 dígitos).

Assim, o quarto indicador utilizado para a análise dos diferentes padrões de especialização dos países nas CGV refere-se à variação da participação das exportações de setores manufatureiros de média e alta intensidade tecnológica ${ }^{5}$ nas exportações totais, entre 1995 e 2011.

Indicador 4: $\Delta$ Exportação de média e alta intensidade tecnológica $=\Delta\left(\operatorname{Exp}_{\mathrm{HT}} / \mathrm{X}\right)$

Onde: $\Delta$ refere-se à variação; Ехрнт às exportações de manufaturados com média e alta intensidade tecnológica $\mathrm{e} ; \mathrm{X}$ às exportações totais.

\section{c. Estatísticas de comércio de bens e serviços do balanço de pagamento: balança comercial e de renda de pagamento pelo uso de propriedade intelectual.}

Anteriormente, discutiu-se o estabelecimento de um sistema de propriedade intelectual internacional como um elemento importante na consolidação e ampliação das CGV por garantir o poder de comando das empresas líderes na distribuição da captura de valor adicionado entre os países participantes. Além disso, a detenção desses direitos de propriedade tem garantido aos países desenvolvidos, fluxos de renda na forma de royalties decorrentes do uso de licenças de tecnologia ou de produtos pelos países em desenvolvimento ao atuarem nas etapas manufatureiras terceirizadas pelas empresas líderes (PINTO et al, 2015; DURAND \& MILBERG, 2018). Em uma linha similar, Carlotto e Pinto (2015) discutem o aumento da dependência dos países em desenvolvimento via aumento das despesas com pagamento pelo uso de propriedade intelectual aos países desenvolvidos.

Com base nessa discussão, sugeri-se que o padrão de especialização dos países nas CGV reflita na composição de suas contas correntes do balanço de pagamento, com alterações da balança comercial, mas também da balança de serviços, mais especificamente a subconta de renda de pagamento pelo uso de propriedade intelectual. Segundo essa discussão, a variação dessas duas contas estaria ocorrendo em direção contrária.

5 Manufaturas de média intensidade tecnológica - produtos automotivos; indústria processada de média tecnologia (fibras sintéticas, produtos químicos...); indústria de engenharia de média tecnologia (motores, máquinas industriais,...). Manufaturas de alta intensidade tecnológica - produtos eletrônicos e elétricos; outros de alta tecnologia (LALL, 2000). 
Diante disso e da ausência de análise empírica desses dados no âmbito das CGVs, são calculadas para os países da amostra entre 1995 e 2011: i.) variação do saldo do pagamento pelo uso de propriedade intelectual ${ }^{6}$ (PIntelec) e; ii.) variação do saldo da balança comercial (BC), expressos respectivamente nas equações 2 e 3 . Com isso, busca-se identificar padrões entre a variação desses dois saldos nos diferentes países de forma a verificar a ideia defendida pelos autores acima de relação inversa entre esses saldos.

$\Delta$ Saldo do pagamento pelo uso de propriedade intelectual $=$

$\Delta$ [crédito (recebimento) de PIntelec - débito (pagamento) de PIntelec] (equação 2)

$\Delta$ Saldo da Balança Comercial $=\Delta[$ crédito da $\mathrm{BC}-$ débito da $\mathrm{BC}]$

Visando reunir essas informações, criou-se o indicador 5 de "Padrão da variação dos saldos de pagamento pelo uso de Propriedade Intelectual e da Balança Comercial”, que refere-se ao Índice PIntelec_BC, calculado a partir da razão desses saldos normalizados em um intervalo entre 0 e 1 .

Indicador 5: Índice PIntelec_BC $=\Delta \mathrm{PIntelec}$ NORM / $\Delta \mathrm{BC}$ NORM

Onde: $\Delta$ refere-se à variação; "PIntelec NoRm" ao saldo normalizado da renda de pagamento pelo uso de propriedade intelectual e; "BC NORM" ao saldo normalizado da balança comercial.

Como tanto o numerador quanto o denominador normalizados ficam num intervalo entre 0 e 1 , o indicador calculado encontra-se no limite entre o intervalo 0 e 100. Números elevados significam que o país apresenta variações positiva no saldo do pagamento de propriedade intelectual simultaneamente a variações negativas na balança comercial, situação esta característica geralmente em países desenvolvidos. Esse comportamento das contas expressa o aumento do recebimento líquido de renda de pagamento pelo uso de propriedade intelectual decorrente de maior exportação líquida de conhecimento, ao mesmo tempo em que passam a despender mais pela maior importação líquida de bens. Já os números mais baixos do indicador, representam o contrário, em geral, os países em desenvolvimento, caracterizando-se como importadores de conhecimento e exportadores de bens. Números intermediários referem-se aos países com variação dos saldos das duas contas ocorrendo na mesma direção, ou dos que são exportadores líquidos de conhecimento e que ainda conseguem obter resultados positivos como exportadores de bens, ou dos que se perpetuam como importadores de conhecimento sem nem mesmo conseguir compensar essa dependência com aumento das exportações de bens. A tabela 1 resume essas informações.

Tabela 1 - Categorização dos padrões da variação dos saldos de renda de uso de propriedade intelectual e da balança comercial.

\begin{tabular}{|c|c|c|}
\hline$\Delta$ Saldo do PIntelec & $\Delta$ Saldo da BC & Indicador 5: \\
\hline+ & - & Valores mais altos \\
\hline+ & + & Valores intermediários \\
- & - & Valores mais baixos \\
\hline- & + & \\
\hline
\end{tabular}

Assim, o quinto indicador expressa não somente os padrões existentes entre variação dos saldos do pagamento pelo uso de propriedade intelectual e da balança comercial, como também indica a magnitude dessas variações. Em geral, quanto mais nos extremos for o valor do indicador, maior será a variação de um dos saldos. Para esses cálculos, utilizaram-se dados do Balanço de Pagamento do FMI.

Todos os cinco indicadores foram calculados para 41 países, selecionados com base na disponibilidade de dados (TIVA-OCDE, CONTRADE e FMI) e nas características gerais dos países. Com exceção do indicador 1 cujo índice foi uma média entre valores de nível e de variação, os indicadores são de variação, de forma a identificar a evolução dos países nos aspectos ressaltados. A tabela 4 em anexo resume o resultado dos indicadores calculados para a amostra.

${ }^{6}$ Cobrança pelo uso de propriedade intelectual engloba pagamentos relativos ao uso de propriedade intelectual advindo de licença de exploração de patentes, fornecimento de tecnologia, assistência técnica, uso de marcas e software... 


\section{DESCRIÇÃO DOS RESULTADOS: ANÁLISE DOS INDICADORES}

A análise isolada dos indicadores mostra algumas evidências referentes às CGV. A primeira refere-se à participação dos países nas cadeias. Os países com o indicador em níveis mais elevados são economias pequenas altamente dependentes de insumos importados, com a demanda externa atuando como mercado consumidor importante para a sua produção, e geralmente atuando em posições intermediárias nas cadeias, tabela 2 em anexo (CORREA, 2016, 2019; BANGA, 2013, UNCTAD, $2013 ; \ldots)$.

Outro aspecto importante observado refere-se ao valor adicionado doméstico das exportações (DVA). Com o indicador, identificou-se que os países que apresentaram maior crescimento do índice de participação nas cadeias foram os que mais perderam valor adicionado doméstico nas exportações, tabela 2 em anexo. A acentuada relação inversa entre esses dois indicadores é confirmada pela elevada correlação negativa, a mais alta entre os indicadores, tabela $3 \mathrm{em}$ anexo. Com base na literatura que considera o DVA como proxy de upgrading econômico, esse resultado converge com as discussões acerca das dificuldades de upgrading funcional e com isso, limitação da participação nas cadeias como mecanismo de aumentar a criação de VA local e também dos possíveis transbordamento para a economia (CORRÊA, 2019, MILBERG \& WINKLER, 2013; TAGLIONI et.al, 2016; BANGA, 2014).

A respeito da importância do setor de serviços sofisticados, percebe-se que os países que mais cresceram nas cadeias globais, não o fizeram via estas atividades, questão essa evidenciada na mesma tabela 2 em anexo. Esse resultado mostra que os países que mais aumentaram o volume de comércio intracadeia não são geralmente os que desenvolvem atividades de serviços intensivas em conhecimento, como por exemplo, atividades de P\&D, incluídas no agregado "serviços de negócios" da base TIVA-OCDE. Isso sugere o baixo potencial de sofisticação do padrão de especialização dos países nas cadeias em termos de atividades desempenhadas (MILBERG \& WINKLER, 2013...).

Sobre o aumento das exportações de manufaturas intensivas em tecnologia, observa-se que dentre os países que mais aumentaram participação nas cadeias, muitos apresentaram sofisticação de suas pautas exportadoras. Ressalta-se que ao desempenhar atividades de processamento e montagem de bens finais, recebem o "título" de exportadores desses bens, em geral, intensivos em tecnologia.

No que tange aos padrões entre variação do saldo da propriedade intelectual e da balança comercial do indicador 5, serão feitos inicialmente comentários a respeito da relação entre essas variáveis, para depois discutirmos os resultados obtidos com o indicador calculado.

O primeiro ponto a ser ressaltado refere-se ao fato de que os países, no geral, apresentaram uma relação contrária entre variação do saldo do pagamento pelo uso de propriedade intelectual e variação do saldo da balança comercial. A alta correlação negativa dessas duas variáveis confirma isso. Com esse resultado, ratifica-se a ideia defendida em Carlotto e Pinto (2015) e Pinto et.al. (2015) de maiores déficits da balança comercial dos países desenvolvidos compensados com maiores superávits na subconta de pagamentos pelo uso de propriedade intelectual, e os países em desenvolvimento apresentando, em geral, resultado em direção contrária. O resultado confirma a hipótese defendida inicialmente de maior dependência tecnológica dos países em desenvolvimento embora os mesmos venham apresentando sofisticação tecnológica de suas exportações. Somente dois países em desenvolvimento destoaram totalmente desse padrão: México (com variação do saldo de propriedade intelectual positivo, e variação do salda BC negativo) e Hungria (com variações positivas em ambos os saldos). A tabela $1 \mathrm{em}$ anexo mostra detalhadamente os dados que deram origem ao indicador 5 .

Sobre este indicador propriamente dito, algumas considerações serão feitas. A primeira delas refere-se à distribuição dos países dentro do intervalo de resultados do indicador. Os Estados Unidos foi o país com o indicador mais alto, cujo valor foi 100, devido à variação do saldo da renda de propriedade intelectual extremamente elevada. Depois dele, vem Japão, cujo valor foi de 0,61, também devido à variação positiva da renda de propriedade intelectual, no entanto, muito inferior a obtida pelos EUA. Assim, para a análise deste indicador, tem que se ter em mente, que o valor mais alto foi o obtido pelos EUA de 100, e todos os demais países da amostra encontrando-se entre 0,61 e 0,01. Esse resultado está coerente com a postura dos EUA no âmbito da OMC, em que defende amplamente a 
institucionalização multilateral dos direitos de propriedade já denominada por autores supracitados como a "diplomacia da propriedade intelectual".

Levando em consideração os padrões de variação dos saldos de propriedade intelectual e da balança comercial (discutidos na tabela anterior) simultaneamente aos valores obtidos do indicador 5 , três comportamentos foram identificados e resumidos na tabela 2 :

Tabela 2 - Categorização dos padrões da variação dos saldos de renda de uso de propriedade intelectual e da balança comercial.

\begin{tabular}{|c|c|c|}
\hline$\Delta$ Saldo do PIntelec & $\Delta$ Saldo da BC & Indicador 5: \\
\hline+ & - & $0,30<$ Ind. $4<0,61+$ EUA \\
+ & + & Ind. $4=0,29$ \\
\hline- & - & Ind. $4<0,29$ \\
\hline- & + & 0
\end{tabular}

- Os países cujo indicador foi mais elevado, maior que 0,30 (em outras palavras, entre 0,30 e 0,61, mais EUA com 100) são aqueles que, em geral, apresentaram o padrão de países desenvolvidos de variação positiva do saldo de propriedade intelectual em paralelo a variação negativa do saldo da balança comercial, caracterizando-se como exportadores líquidos de conhecimento e importadores líquidos de bens. No extremo mais alto, além dos EUA, estão o Japão, Reino Unido e França, representando aqueles cujo recebimento de renda de pagamento de uso de propriedade intelectual se encontra nos patamares mais elevados. Alguns poucos países da amostra dentro deste intervalo conseguiram ainda obter variação positiva em ambas as contas, como Alemanha, Suíça e Suécia, que por o denominador ser mais elevado, acabou gerando indicador em patamar mais próximo do limite inferior desse intervalo. Neste caso, os países sendo exportadores líquidos de conhecimento e de bens.

- Os países cujo indicador foi intermediário, igual a 0,29, foram aqueles que, em geral, apresentaram variação negativa das duas contas. O saldo da subconta de pagamento de propriedade intelectual desses países tem piorado, sem haver uma contrapartida em termos de melhora da balança comercial. Entre esses, identificam-se países desenvolvidos e em desenvolvimento como Portugal, Itália, Hong Kong, Camboja, Filipinas e outros. Esses países caracterizam-se por serem importadores líquidos de conhecimento e de bens.

- Os países cujo indicador foi mais baixo, inferior 0,29, foram aqueles que, em geral, apresentaram o padrão de países em desenvolvimento de variação negativa do saldo de propriedade intelectual em paralelo a variação positiva do saldo da balança comercial, cujo padrão foi o mais frequente na amostra. Ressalta-se que no extremo mais baixo e até um pouco isolado dos demais países deste intervalo, estão Irlanda, Cingapura e China, os dois primeiros devido ao numerador muito baixo, e o terceiro, devido ao denominador muito elevado.

Apesar dos indicadores isolados evidenciarem algumas tendências referentes às CGV, optou-se para o mapeamento dos padrões de especialização dos países nas cadeias por uma análise conjunta desses indicadores considerando-se simultaneamente os aspectos ressaltados por eles. Diante da disponibilidade de uma grande quantidade de informações, foi utilizada a técnica de agrupamento ou clusters $^{7}$, de forma a identificar padrões entre os países da amostra. Essa análise contribui também para identificar padrões mais específicos entre os países em desenvolvimento, destacando-se a heterogeneidade existente entre eles.

A escolha metodológica se justifica pela adequação de análises exploratórias de dados quando não houver modelo teórico ou então hipóteses iniciais (KUBRUSLY apud KUPFER et.al., 2002: JOHNSON et.al., 2007). Ressalta-se ainda que embora a metodologia não expresse relação de causalidade entre as variáveis, o mapeamento contribui para verificar empiricamente se os dados

\footnotetext{
${ }^{7}$ A técnica de agrupamento consiste na criação de grupos para elementos da amostra com características similares, reunidos a partir de medidas de distância que definirão as (dis)similaridades entre esses elementos. Quando não se sabe a priori o número de grupos a serem criados, estes se formam hierarquicamente, com os elementos se reunindo por etapa, respeitando alguma técnica aglomerativa. Assim, criam-se grupos cada vez maiores, mas em menor quantidade, sendo a quantidade escolhida baseada nas características priorizadas (JOHNSON \& WICHERN, 2007).
} 
convergem com as discussões referentes à maior dependência tecnológica dos países em desenvolvimento via participação nas $\mathrm{CGV}^{8}$.

No presente trabalho, os clusters foram calculados para os 41 países da amostra e os cinco indicadores, utilizando-se diferentes técnicas aglomerativas ${ }^{9}$. Ressalta-se ainda que, como o objetivo do presente trabalho é analisar os distintos padrões de especialização dos países nas CGV e verificar se essas diferenças são acompanhadas de maior autonomia ou dependência tecnológica dos países via conta de renda de pagamento pelo uso de propriedade intelectual, alguns países foram deslocados dos grupos originais de forma a ficar mais claro padrões particulares nas variáveis de serviços sofisticados e de renda de propriedade intelectual.

A técnica de aglomeração gerou cinco grupos com características especificas entre eles, sugerindo não somente diferenças dos padrões de especialização entre os países desenvolvidos e em desenvolvimento, com também diferenças internas a esses dois grupos. A tabela 3 resume a composição dos grupos (distribuídos nas colunas) e as respectivas características em termos de indicadores que os diferem uns dos outros. Como os indicadores 1 e 2 apresentaram variação somente em uma direção (o primeiro só positivo e o segundo negativo), optou-se por utilizar a classificação "baixo, médio e alto", que refere-se a comparação entre a média do grupo e a média da amostra, isto é, se a média do grupo é menor, no entorno ou maior que a média da amostra. Para os indicadores que apresentaram tanto variação positiva quanto negativa, optou-se por utilizar o sinal de maior ">" ou menor " $<$ " e quando variação muito significativa, os sinais " $>>$ " ou " $<<$ ". As notas de rodapé na tabela referem-se às exceções à regra, com algum país não se encaixando no padrão identificado. Em anexo, encontram-se os dados detalhados dos países organizados de acordo com os grupos gerados pela técnica de cluster.

Tabela 3 - Mapeamento dos países nas CGV.

\begin{tabular}{|c|c|c|c|c|c|}
\hline & Grupo 1 & Grupo 2 & Grupo 3 & Grupo 4 & Grupo 5 \\
\hline Indicadores: & $\begin{array}{c}\text { EUA } \\
\text { R.Unido } \\
\text { Japão } \\
\text { França } \\
\text { Espanha } \\
\text { Áustria } \\
\text { Israel } \\
\text { Suécia } \\
\text { Suíça } \\
\text { Alemanha }\end{array}$ & $\begin{array}{c}\text { Itália } \\
\text { Portugal } \\
\text { Cingapura } \\
\text { Irlanda } \\
\text { Holanda } \\
\text { Hong Kong } \\
\text { Índia } \\
\text { Costa Rica }\end{array}$ & $\begin{array}{l}\text { Malásia } \\
\text { Tailândia } \\
\text { Coreia } \\
\text { Camboja } \\
\text { Eslovênia } \\
\text { Bulgária } \\
\text { Rep. Checa } \\
\text { Eslováquia } \\
\text { Polônia } \\
\text { Hungria }\end{array}$ & $\begin{array}{c}\text { China } \\
\text { Indonésia } \\
\text { Filipinas } \\
\text { Turquia } \\
\text { Colômbia } \\
\text { México }\end{array}$ & $\begin{array}{c}\text { Austrália } \\
\text { Brasil } \\
\text { Canadá } \\
\text { Rússia } \\
\text { Chile } \\
\text { Argentina } \\
\text { África do Sul }\end{array}$ \\
\hline 1) IP & Médio & Médio & Alto & Baixo & Baixo \\
\hline 2) $\triangle \mathrm{DVA}$ & Médio & Baixo & Alto & Baixo & Baixo \\
\hline 3) $\Delta \mathbf{V A X s} \mathbf{A}_{\mathrm{A}, \mathrm{B}, \mathrm{C}}$ & $(>0)$ & $(\gg>0)$ & $(<0)$ & $(<0)$ & $(<0)$ \\
\hline 4) $\Delta \mathrm{Exp} H \mathrm{HT}$ & $(<<0)$ & $(>0)$ & $(>>0)$ & $(>>0)$ & $(<<0)$ \\
\hline 5) $\Delta$ Prop.Intelec_BC & $\begin{array}{c}=0,45 \\
(+-) \text { ou }(++)\end{array}$ & $\begin{array}{c}=0,21 \\
(-+) \text { ou (- -) }\end{array}$ & $\begin{array}{c}=0,28 \\
(-+) \text { ou }(--)^{1}\end{array}$ & $\begin{array}{c}=0,25 \\
(-+) \text { ou }(--)^{2}\end{array}$ & $\begin{array}{c}=0,23 \\
(-+) \text { ou }(--)\end{array}$ \\
\hline
\end{tabular}

Fonte: elaboração própria. Legenda: $\Delta$ (variação); IP (índice de participação); VAXsA,B,C (saldo do VA de serviços sofisticados nas exportações); ExpHT (exportações de manufaturas de média e alta tecnologia); Alto (quando média do grupo maior que a média da amostra); Médio (média do grupo igual ou no entorno da média da amostra); Baixo (quando muito abaixo da média da amostra); $>$ ou $<$ (variação média); > ou $<<$ (variação significativa). Notas: 1.Hungria: PIntelec_BC $(++)$ e México: PIntelec_BC $(+-)$.

\footnotetext{
${ }^{8}$ A mesma metodologia foi utilizada por Corrêa $(2016$; 2019) em que a participação e evolução nas CGV via upgrading foi definida a partir da combinação de indicadores. Recentemente, Smichowski et.al.(2018) faz análise similar, discutindo ainda a adequação da metodologia em questão diante da possibilidade de regressões mascararem a heterogeneidade das relações entre as variáveis por subgrupos de países quando estes muito distintos (RODRIGUES \& RODRIK apud SMICHOWSKI et.al.,2018).

${ }^{9}$ Clusters calculados através do software estatístico SPSS, utilizando-se o agrupamento hierárquico, com a distância entre os elementos ficando elevada (maior heterogeneidade entre eles) com resultados abaixo de 5 grupos.
} 
Os grupos formados são descritos a seguir, sendo classificados segundo características de destaque em cada um deles:

Grupo 1: países desenvolvidos com melhora dos saldos de pagamento pelo uso de propriedade intelectual e aumento dos serviços intensivos em conhecimento.

O grupo 1 é formado por países desenvolvidos que se caracterizam por apresentar, em geral, melhora dos saldos de renda pelo uso de propriedade intelectual e variação negativa de balança comercial (alguns poucos apresentam melhora em ambas as contas) simultaneamente ao aumento da importância da criação de valor adicionado em serviços sofisticados nas exportações desses países. Esses países apresentaram também redução da exportação de manufaturas intensivas em tecnologia, e índice de participação nas cadeias em torno da média da amostra.

Grupo 2: países desenvolvidos e em desenvolvimento com piora dos saldos de pagamento pelo uso de propriedade intelectual e aumento significativo dos serviços intensivos em conhecimento.

O grupo 2 é formado por países desenvolvidos e em desenvolvimento que se caracterizam por apresentarem aumento muito significativo da importância dos serviços sofisticados nas exportações e piora dos saldos de renda de pagamento de uso propriedade intelectual no período. Para alguns, essa deterioração foi acompanhada por saldos crescentes da balança comercial, enquanto para outros, houve também deterioração na balança comercial. Ressalta-se ainda que o valor médio do indicador 5 de padrões desses saldos foi o mais baixo de toda a amostra, e isso impulsionado pelos déficits acentuados e crescentes da conta de pagamento pelo uso de propriedade intelectual ${ }^{10}$.

Grupo 3: países em desenvolvimento com piora dos saldos de pagamento pelo uso de propriedade intelectual, aumento significativo das exportações de manufaturas intensivas em tecnologia, índice de participação nas cadeias alto e elevada perda de valor adicionado doméstico nas exportações.

O grupo 3 é formado por países em desenvolvimento que se caracterizam por apresentar aumento significativo das exportações de manufaturas intensivas em tecnologia e índice de participação nas cadeias em patamar mais elevado da amostra em paralelo a maior perda obtida em termos de valor adicionado doméstico nas exportações. Outra característica identificada refere-se à piora dos saldos de renda de pagamento de uso propriedade intelectual no período acompanhada quase que integralmente por melhora no saldo balança comercial. Em alguns países como Polônia, Bulgária e Camboja, a piora ocorreu em ambas às contas. Hungria destoa deste padrão apresentando melhora em ambas as contas.

Grupo 4: países em desenvolvimento com piora dos saldos de pagamento pelo uso de propriedade intelectual, aumento significativo das exportações de manufaturas intensivas em tecnologia e índice de participação nas cadeias baixo.

O grupo 4 assemelha-se ao grupo 3 destoando apenas no índice de participação nas cadeias, que nesse grupo encontra-se em nível baixo. É formado por países em desenvolvimento que se caracterizam por apresentar aumento significativo das exportações de manufaturas intensivas em tecnologia, mas baixa perda de valor adicionado doméstico. Estes países também vêm apresentando piora dos saldos de renda de pagamento pelo uso propriedade intelectual acompanhada pela maioria por melhora no saldo da balança comercial. México destoa deste padrão apresentando melhora do saldo de renda de pagamento pelo uso de propriedade intelectual.

Grupo 5: países desenvolvidos e em desenvolvimento com índice de participação nas cadeias baixo e sem expressividade nos setores de serviços e de manufaturas intensivas em tecnologia.

O grupo 5 é formado por países desenvolvidos e em desenvolvidos que se caracterizam por apresentar índice de participação nas cadeias baixo. Além disso, a variação dos serviços sofisticados foi menor que a média da amostra em paralelo a redução significativa das exportações de manufaturas

\footnotetext{
${ }^{10}$ Essa última informação especificamente é obtida no detalhamento do indicador 5 disponível na tabela 1 em anexo.
} 
intensivas em tecnologia. A grande maioria apresentou piora nos saldos de propriedade intelectual acompanhados por melhora na balança comercial.

A seguir, uma descrição das diferenças existentes entre os grupos, destacando-se os padrões de especialização de cada um deles, obtidos a partir da análise conjunta dos indicadores.

Inicialmente, ressalta-se que somente o grupo 1 - formado por países desenvolvidos apresentou aumento dos saldos das contas de pagamento pelo uso de propriedade intelectual geralmente em paralelo a piora dos saldos da balança comercial. Esse comportamento das contas evidencia quem são os exportadores de conhecimento, tecnologia e marca, e como o investimento em ativos intangíveis altamente protegidos por direito de propriedade intelectual garante o poder de comando nas cadeias, e com isso, aprofundando as assimetrias entre países desenvolvidos e em desenvolvimento. $\mathrm{O}$ fato das grandes corporações (sediadas, em geral, nesses países) restringirem-se às atividades de serviços sofisticadas terceirizando internacionalmente todas as demais (principalmente as etapas finais de montagem) explica a deterioração das contas comerciais desses países, bem como a maior participação de serviços intensivos em conhecimento em termos de VA nas exportações totais.

Nos demais grupos, o padrão dos saldos de propriedade intelectual e balança comercial foi o contrário, com piora no primeiro e melhora, em geral, no segundo. Neste caso, evidencia-se a maior participação nas cadeias vir acompanhada frequentemente por melhora comercial, às vezes, ainda por sua sofisticação, e que ao produzirem bens mais intensivos em tecnologia com processos produtivos altamente protegidos por direito de propriedade, podem ter suas contas de pagamento pelo uso de propriedade intelectual do balanço de pagamento agravadas.

Entre esses grupos, apenas o grupo 2 obteve aumento significativo da participação dos serviços intensivos em conhecimento nas exportações, ressaltando que esse aumento foi muito mais expressivo do que o aumento obtido pelo grupo 1. Isso evidencia que a terceirização também envolve atividades de serviços sofisticados, com alguns países em desenvolvimento ampliando a atuação nesses segmentos devido ao acúmulo de competências específicas em determinadas áreas. No entanto, como as estratégias de internacionalização tecnológica são hierarquizadas e seletivas, esses países ainda se mantêm como importadores de conhecimento. Ressalta-se inclusive, o agravamento mais acentuado dos déficits na conta de pagamento pelo uso de propriedade intelectual por esses países.

Já nos grupos 3 e 4, identificou-se o aumento significativo da importância das manufaturas intensivas em tecnologia, sendo que no 3, esse aumento ocorrendo em paralelo ao aumento do índice de participação nas cadeias, cujo indicador se encontra em nível mais elevado da amostra. Ressalta-se ainda que esse índice mais elevado foi acompanhado de maior perda de valor adicionado doméstico nas exportações. $\mathrm{O}$ aumento expressivo de exportações de manufaturas intensivas em tecnologia e o elevado crescimento da participação nas cadeias de valor acompanhado de perda acentuada de VA nas exportações sugerem uma sofisticação da estrutura comercial através da atuação em atividades de processamento e montagem, dado que os participantes de etapas produtivas finais de montagem recebem o "título" de exportadores de bens finais.

Em um caminho diferente, encontra-se o grupo 5, com baixa participação nas cadeias de valor e com redução da importância tanto das manufaturas intensivas em tecnologia como também dos serviços intensivos em conhecimento. Com esses indicadores, poderíamos classificá-los como uma especialização indefinida, mas que numa observação mais atenciosa sobre os países do grupo, pode-se dizer que são, em geral, abundantes em recursos naturais e, com isso, sua participação via fornecimento de matérias-primas. Esse fato reflete tanto no baixo índice de participação nas cadeias (atuação no extremo da cadeia de valor, quase que exclusivamente a jusante -VAX*) como também pela baixa perda de valor adicionado doméstico nas exportações devido a pouca alteração da pauta exportadora desses países após a inserção. A tabela 4 sintetiza as diferenças entre os grupos definindo o padrão de especialização a partir da combinação dos indicadores.

Com os 5 grupos obtidos, observou-se a existência de diferentes padrões de especialização dos países nas cadeias, principalmente entre os países em desenvolvimento, evidenciando a heterogeneidade existente entre eles. Os dados mostraram que os países desenvolvidos analisados na amostra apresentaram, em geral, um padrão de especialização específico, baseado em serviços 
intensivos em conhecimento, e atuando na grande maioria, como exportadores líquidos de tecnologia. Já os países em desenvolvimento apresentaram diferentes possibilidades de especialização nas cadeias como, por exemplo, uma atuação em atividades de serviços sofisticados, ou em atividades de processamento e montagem de manufaturas intensivas em tecnologia ou mesmo, como fornecedores de recursos naturais, e em todos os casos atuando como importadores líquidos de tecnologia.

Tabela 4 - Padrões de especialização nas cadeias e capacitação tecnológica

\begin{tabular}{|c|c|c|c|c|}
\hline \multirow{2}{*}{$\begin{array}{l}\frac{\text { Capacidade Tecnológica: }}{\text { Intensidade de participação }} \\
\text { Setores: }\end{array}$} & \multirow{2}{*}{$\begin{array}{c}\begin{array}{c}\text { Exportadores líquido de } \\
\text { conhecimento/tecnologia }\end{array} \\
\text { IP médio }\end{array}$} & \multicolumn{3}{|c|}{$\begin{array}{l}\text { Importadores líquido de } \\
\text { conhecimento/tecnologia }\end{array}$} \\
\hline & & IP alto & IP médio & IP baixo \\
\hline Serviços sofisticados & G1 - Países desenvolvidos & & $\begin{array}{l}\text { G2 - Países desenv. e } \\
\text { em desenvolvimento }\end{array}$ & \\
\hline $\begin{array}{l}\text { Manufaturas intensivas em } \\
\text { tecnologia }\end{array}$ & & $\begin{array}{l}\text { G3 - Países em } \\
\text { desenvolvimento }\end{array}$ & & $\begin{array}{l}\text { G4 - Países em } \\
\text { desenvolvimento }\end{array}$ \\
\hline $\begin{array}{l}\text { Indefinido (Recursos } \\
\text { naturais) }\end{array}$ & & & & $\begin{array}{l}\text { G5 - Países em } \\
\text { desenvolvimento }\end{array}$ \\
\hline
\end{tabular}

A principal via adotada pelos países em desenvolvimento é a especialização em manufaturas intensivas em tecnologia, em que a queda acentuada do valor adicionado doméstico e o aumento significativo das exportações de manufaturas intensivas em tecnologia expressariam uma atuação nas cadeias em atividades de processamento e montagem. Outra via encontrada foi a especialização nas cadeias em atividades de serviços, ressaltando-se a existência de pouquíssimos países em desenvolvimento com aumento expressivo do valor adicionado em serviços intensivos em conhecimento. E por fim, uma especialização em recursos naturais, sem grandes perdas em termos de captura de VA, mas também a importância do comércio intracadeia com pouca expressividade nas exportações totais. Independente da via adotada, observou-se que a maior participação nas cadeias foi acompanhada de perda de VA nas exportações destes países, e a intensidade do aumento da primeira altamente correlacionada com a intensidade da redução do segundo.

Identificou-se ainda que os países que mais aumentaram a participação nas cadeias seguiram um padrão de especialização específico de melhora das contas comerciais, sofísticação da pauta exportara (em termos brutos) e redução de participação de atividades sofisticadas de serviço, o que em conjunto se interpreta como uma atuação em atividades de processamento e montagem das manufaturas com baixa capacidade de criação de valor adicionado. Esse padrão foi adotado por países da periferia, e neste caso, considerando-se inclusive a periferia europeia, como alguns países do leste europeu. Isso acontece por os países periféricos que se encontram próximos aos países centrais absorverem diretamente as atividades terceirizadas pelas grandes firmas sediadas nestes últimos, corroborando o que a literatura discute sobre as cadeias de valor serem mais regionais do que globais.

Com os grupos criados, identificou-se também que mesmo com o paradigma de produção fragmentada internacionalmente, e que muda a distribuição geográfica mundial da produção e comércio com possivelmente sua sofisticação, a dependência tecnológica dos países em desenvolvimento em relação aos desenvolvidos acentuou-se, com os primeiros subordinados ao segundo através da conta de pagamento pelo uso de propriedade intelectual. Embora atualmente os países em desenvolvimento sejam frequentemente os produtores de manufaturas intensivas em tecnologia, traduzindo-se frequentemente em saldos comerciais superavitários, os países desenvolvidos são os desenvolvedores das tecnologias utilizadas nesses processos produtivos e que são altamente protegidas, contribuindo para a manutenção da estrutura de governança garantidora de posições monopolistas das grandes corporações sediadas, em geral, nos países desenvolvidos. Neste caso, identificam-se os ganhos obtidos pela participação nas cadeias não através de estatísticas de comércio, mas de estatísticas que mensurem esses ativos intangíveis.

E por fim, destaca-se que entre os países que apresentaram diminuição dos saldos das contas de pagamento pelo uso de propriedade intelectual, observa-se que o pior resultado em termos de dependência tecnológica foi o do grupo com padrão de especialização em serviços intensivos em 
conhecimento. Este fato mostra que o elevado pagamento por uso de propriedade intelectual não é, em geral, acompanhado por saldos positivo da balança comercial dada a sua especialização em serviços. Assim, interpreta-se, por um lado, como uma sofisticação desses países em termos de atividades desempenhadas (upgrading funcional) contribuindo para amenizar a redução do valor adicionado decorrente de maior participação nas cadeias produtivas, diante dos efeitos de longo prazo dessas atividades sobre a economia em termos de transbordamento. Mas por outro lado, acentua-se a dependência tecnológica atual em termos de pagamento pelo uso de conhecimento desenvolvido em outro lugar, o que nos faz refletir sobre a terceirização também envolver serviços sofisticados, e estes vinculados a patentes, marcas e software desenvolvidos por terceiros e altamente protegidos internacionalmente. Seria importante uma análise mais minuciosa das atividades desenvolvidas por esses países, e entender se essa atuação não levaria a problemas crônicos de restrição no balanço de pagamento, principalmente quando se tratar de país em desenvolvimento já com problemas usuais na balança de serviço. No entanto, essa análise foge do escopo do presente trabalho.

\section{CONCLUSÃO:}

Em vista dos efeitos da participação dos países em desenvolvimento nas CGV em termos de aprofundamento da industrialização e potencias transbordamentos para o restante da economia e da discussão paralela a respeito da propagação das CGV simultaneamente ao fortalecimento da institucionalidade internacional de direito de propriedade intelectual, buscou-se analisar empiricamente se a participação nas cadeias em padrões de especialização específicos tem sido acompanhada de maior dependência tecnológica dos países em desenvolvimento em termos de pagamento pelo uso de propriedade intelectual.

Identificou-se com a metodologia que os países desenvolvidos da amostra apresentaram geralmente um padrão de especialização em serviços intensivos em conhecimento, enquanto os países em desenvolvimento, diferentes alternativas, como uma atuação em atividades de serviços sofisticados, ou em montagem de manufaturas intensivas em tecnologia ou como fornecedores de recursos naturais.

Independentemente do padrão de especialização seguido, observou-se um aprofundamento da dependência tecnológica dos países em desenvolvimento em relação aos desenvolvidos, com os primeiros subordinados ao segundo através da conta de pagamento pelo uso de propriedade intelectual. Assim, embora os países em desenvolvimento sejam frequentemente os produtores de manufaturas intensivas em tecnologia, e que refletem geralmente nos crescentes saldos comerciais superavitários, os países desenvolvidos são os desenvolvedores e proprietários da tecnologia utilizada nesses processos produtivos. Ressalta-se ainda que mesmo para os países em desenvolvimento em padrões de especialização baseado em serviços sofisticados, a dependência tecnológica via conta de pagamento pelo uso de propriedade intelectual também foi elevada. Esse resultado é prejudicado ainda pelo fato desses países não conseguirem nem mesmo apresentar superávits na balança comercial, cuja composição da estrutura do BP pode levar a problemas mais crônicos de restrição no longo prazo.

O resultado obtido com a metodologia converge com a literatura recente sobre a consolidação do sistema internacional de propriedade intelectual ampliar as posições monopolistas das grandes corporações sediadas, em geral, nos países desenvolvidos, acentuando-se assimetrias tecnológicas existentes entre esses países e os em desenvolvimento. Como resultado, identifica-se a manutenção da divisão internacional do trabalho vigente também no âmbito do paradigma produtivo das CGV, que antes se expressava na distribuição global da produção e do comércio de bens, e que agora se traduz em termos de produção e comércio de tecnologia e conhecimento inerentes ao comércio desses bens.

\section{BIBLIOGRAFIA}

AGUIAR de MEDEIROS, C., \& TREBAT, N.(2017). Inequality and Income Distribution in Global Value Chains. Journal of Economic Issues,51(2), 401-408.

BALDWIN, R (2012). Global Supply Chains: Why they Emerged, Why they Matters, and Where They Are Going. Fung Global Institute, Working Paper 2012-01.

BANGA, R (2013). Measuring value in global value chains.Unit of Economic Cooperation and Integration amongst Developing Countries (ECIDC) - UNCTAD Background paper n. RVC-8. 
CARLOTTO, M. C.; PINTO, J. P. G. (2015). A divisão internacional do trabalho no século XXI: um estudo sobre o peso da propriedade intelectual na relação EUA -América Latina. Carta Internacional, v.10, p. 94-113.

CORREAA, L. M. (2016). Trajetórias dos países em desenvolvimento nas cadeias globais de valor: upgrading, estágio produtivo e mudança estrutural. Tese (doutorado) - Universidade Federal do Rio de Janeiro, Instituto de Economia, 2016.

CORRÊA, L. M.; PINTO, E. C.; CASTILHO (2019), M.R. Mapeamento dos padrões de atuação dos países nas Cadeias Globais de Valor e os ganhos em termos de mudança estrutural. Econ. soc., Campinas, v. 28, n. 1, p. 89-122, abr.2019.

DURAND, C; MILBERG, W. (2018) Intellectual Monopoly in Global Value Chains. Working Papers 1807, New School for Social Research, Department of Economics. https://ideas.repec.org/p/new/wpaper/1807.html

ERNEST, D. and L. KIM, "Global production networks, knowledge diffusion and local capability formation", Research Policy, 34, 1417-1429, 2002.

HUMPHREY, J., SCHMITZ, H. How does insertion in global value chains affect upgrading in industrial clusters?, Regional Studies, 36:1017-1027, 2002.

JOHNSON, R. e D. WICHERN (2007).Applied Multivariate Statistical Analysis.Editora Pearson, New Jersey, 2007.

JOHNSON, R. C., \& NOGUERA, G. (2012). Accounting for intermediates: production sharing and trade in value added. Journal of international Economics, 86(2):224-236.

KOOPMAN, R.; WANG, Z.; WEI, S. How much of Chinese export is really made in China? Assessing domestic value-added when processing trade is pervasive. Washington: NBER, Mar. 2008. (Working Paper, n. 14.109).

KUPFER, D. \& HASENCLEVER, L.(2002). Economia Industrial. Editora Campus.

MEMEDOVIC, O. e L. IAPADRE. "Structural Change in the World Economy: Main Features and Change", UNIDO, Research and Statistics Branch, Working Paper no. 24/2009.

MILBERG, W. e D. WINKLER. Outsourcing Economics: global value chains in capitalist development. New York. Cambridge University Press, 2013.

MIRANDA,P.C. A internacionalização das atividades tecnológicas e inserção dos países em desenvolvimento: uma análise baseada em dados de patentes. Tese de Doutorado- UNICAMP, 2014.

PAGANOS, U.(2014). The crisis of intellectual monopoly capitalism. Cambridge Journal of Economics, 38(6),1409-1429.

PINTO, E. C., FIANE, R. e CORREAA, L. M. Dimensões da abordagem da Cadeia Global de Valor: Upgrading, Governança, Políticas Governamentais e Propriedade Intelectual. Brasília: IPEA, 2015. Texto para Discussão, no. 2155.

SARTI, F. e C. HIRATUKA, (Coords.). Perspectivas do investimento na indústria. Rio de Janeiro: Synergia:UFRJ,Instituto de Economia;Campinas: UNICAMP, Instituto de Economia, 2010.

SMICHOWSKI, B., DURAND, C., KNAUSS, S.(2018). Participation in global value chains and varieties of development patterns. $<$ hal-01817426>

STURGEON, T. \& G. GEREFFI (2009), Measuring Success in the Global Economy: International Trade, Industrial Upgrading, and Business Function Outsourcing in Global Value Chains, Transitional Corporations, Vol. 18, no. 2, pp. 1-36.

STURGEON, T.\& O. MEMEDOVIC. Mapping Global Value Chains: Intermediate Goods Trade and Structural Change in the World Economy. Development Policy and Strategic Research Branch Working Paper 05/2010. Vienna: UNIDO.

TAGLIONI, D. \& WINKLER, D.(2016) Making Global Value Chains Work for Development. Washington D.C.: The World Bank

UNCTAD (2013) - WIR13. World Investment Report 2013: Global Value Chains: Investiment and Trade for development. New York and Geneva: United Nations.

UNIDO, 2013. Industrial Development Report 2013: Sustaining Employment Growth: The Role of Manufacturing and Structural Change. Viena 


\begin{tabular}{|c|c|c|c|c|c|c|c|c|c|c|}
\hline & & & & & & & & & & \\
\hline ANEX & & & & & & & & Números & lizados & Indicador 5: \\
\hline & & & & & P.Intelec & BC & $\mathrm{PI} / \mathrm{BC}$ & P.Intelec & BC & PIntelec_BC \\
\hline Tabela & Propr & ade I & lectual e & USA & 63876 & -566474 & $-0,11$ & 1 & 0,01 & 100 \\
\hline & & ança & mercial: & Japan & $12.964,89$ & $-87.483,44$ & $-0,15$ & 0,37 & 0,62 & 0,61 \\
\hline & & & & U. Kingdom & 4992,99 & $-132889,16$ & $-0,04$ & 0,28 & 0,56 & 0,49 \\
\hline & & & & France & 5266,29 & $-101701,85$ & $-0,05$ & 0,28 & 0,6 & 0,47 \\
\hline & & & & Sweden & 4831,41 & 6075,69 & 0,8 & 0,27 & 0,74 & 0,37 \\
\hline & & & & India & $-2427,78$ & $-160737,77$ & 0,02 & 0,18 & 0,52 & 0,35 \\
\hline 1 avera & iuicat & es sei & onauos & Switzerland & 3789,81 & 24959,64 & 0,15 & 0,26 & 0,76 & 0,34 \\
\hline & & & & Spain & 1070,15 & $-43202,06$ & $-0,02$ & 0,23 & 0,67 & 0,34 \\
\hline Indicadores & 1) & 2) & 3) & Turkey & -556 & -76046 & 0,01 & 0,21 & 0,63 & 0,33 \\
\hline & IP & DVA & DVAserv & Germany & 5839,39 & 157942,82 & 0,04 & 0,29 & 0,93 & 0,31 \\
\hline Hungary & 0,43 & $-0,19$ & $-0,01$ & Austria & 117,73 & $-5997,65$ & $-0,02$ & 0,22 & 0,72 & 0,3 \\
\hline Korea & 0,42 & $-0,19$ & 0,02 & Greece & $-429,21$ & $-23458,65$ & 0,02 & 0,21 & 0,7 & 0,3 \\
\hline Slovak & 0,42 & $-0,15$ & $-0,02$ & Mexico & 91,85 & $-3369,18$ & $-0,03$ & 0,21 & 0,72 & 0,3 \\
\hline Czech Rep. & 0,41 & $-0,15$ & $-0,02$ & Romania & $-227,51$ & $-11504,68$ & 0,02 & 0,21 & 0,71 & 0,3 \\
\hline Poland & 0,38 & $-0,16$ & 0,02 & Tunisia & 15,41 & $-2757,78$ & $-0,01$ & 0,21 & 0,73 & 0,3 \\
\hline Malaysia & 0,37 & $-0,1$ & $-0,01$ & Italy & $-1873,94$ & $-63781,65$ & 0,03 & 0,19 & 0,65 & 0,29 \\
\hline Thailand & 0,36 & $-0,15$ & 0 & Israel & 52,4 & $-100,6$ & $-0,52$ & 0,21 & 0,73 & 0,29 \\
\hline Slovenia & 0,36 & $-0,04$ & 0,02 & Cambodia & $-9,1$ & $-1813,65$ & 0,01 & 0,21 & 0,73 & 0,29 \\
\hline Chile & 0,35 & $-0,06$ & $-0,01$ & Portugal & $-315,69$ & $-11053,5$ & 0,03 & 0,21 & 0,71 & 0,29 \\
\hline Singapore & 0,34 & 0,01 & 0,06 & Philippines & $-339,62$ & $-11484,04$ & 0,03 & 0,21 & 0,71 & 0,29 \\
\hline Bulgaria & 0,34 & $-0,1$ & 0,02 & Bulgaria & $-121,89$ & $-3847,58$ & 0,03 & 0,21 & 0,72 & 0,29 \\
\hline Ireland & 0,34 & $-0,05$ & 0,14 & Hungary & 189,1 & 6354,44 & 0,03 & 0,22 & 0,74 & 0,29 \\
\hline Cambodia & 0,33 & $-0,24$ & 0,01 & Costa Rica & $-203,98$ & $-4550,63$ & 0,04 & 0,21 & 0,72 & 0,29 \\
\hline Austria & 0,33 & $-0,06$ & 0,02 & Slovak Rep. & $-104,3$ & 146,64 & $-0,71$ & 0,21 & 0,73 & 0,29 \\
\hline Japan & 0,33 & $-0,09$ & 0 & Slovenia & $-309,45$ & $-99,29$ & 3,12 & 0,21 & 0,73 & 0,29 \\
\hline Russia & 0,33 & 0 & 0 & Hong Kong & $-1168,62$ & $-23997,72$ & 0,05 & 0,2 & 0,7 & 0,29 \\
\hline Germany & 0,32 & $-0,11$ & 0,04 & Peru & $-161,56$ & 11859,56 & $-0,01$ & 0,21 & 0,74 & 0,28 \\
\hline India & 0,32 & $-0,15$ & 0,06 & Colombia & $-336,95$ & 8672,22 & $-0,04$ & 0,21 & 0,74 & 0,28 \\
\hline$\ldots .$. & & & & Chile & $-670,16$ & 9391,31 & $-0,07$ & 0,21 & 0,74 & 0,28 \\
\hline China & 0,26 & 0,01 & 0,01 & Czech Rep. & $-854,34$ & 9301,4 & $-0,09$ & 0,2 & 0,74 & 0,27 \\
\hline Colombia & 0,26 & 0,01 & 0 & Poland & -2097 & -16909 & 0,12 & 0,19 & 0,71 & 0,27 \\
\hline Hong Kong & 0,25 & 0,01 & 0,06 & Indonesia & $-940,03$ & $27.292,00$ & $-0,034$ & 0,2 & 0,76 & 0,26 \\
\hline Canada & 0,25 & 0,01 & 0,02 & Argentina & $-1544,14$ & 10013,42 & $-0,15$ & 0,19 & 0,74 & 0,26 \\
\hline United States & 0,25 & $-0,04$ & 0,06 & Korea & $-847,1$ & 35608,2 & $-0,02$ & 0,2 & 0,77 & 0,26 \\
\hline Brazil & 0,24 & $-0,03$ & 0,02 & South Africa & $-1734,93$ & 4570,71 & $-0,38$ & 0,19 & 0,73 & 0,26 \\
\hline Argentina & 0,22 & $-0,08$ & 0 & Malaysia & $-1019,4$ & 46041,8 & $-0,02$ & 0,2 & 0,79 & 0,26 \\
\hline & & & & Thailand & $-2435,1$ & 20153,67 & $-0,12$ & 0,18 & 0,75 & 0,24 \\
\hline & & & & Australia & $-2422,11$ & 26980,7 & $-0,09$ & 0,18 & 0,76 & 0,24 \\
\hline & & & & Brazil & $-2949,82$ & 30720,36 & $-0,1$ & 0,18 & 0,77 & 0,23 \\
\hline & & & & Canada & $-5913,21$ & $-25239,04$ & 0,23 & 0,14 & 0,7 & 0,2 \\
\hline & & & & Russian & $-5274,14$ & 176563,7 & $-0,03$ & 0,15 & 0,96 & 0,16 \\
\hline & & & & Netherlands & $-8337,59$ & 66108,84 & $-0,13$ & 0,11 & 0,81 & 0,14 \\
\hline & & & & China & $-13605,81$ & 210650,64 & $-0,06$ & 0,05 & 1 & 0,05 \\
\hline & & & & Singapore & $-16328,43$ & 62863,23 & $-0,26$ & 0,01 & 0,81 & 0,02 \\
\hline & & & & Ireland & $-17371,36$ & 20241,72 & $-0,86$ & 0,01 & 0,75 & 0,01 \\
\hline
\end{tabular}

Tabela 3 - Matriz de correlação

\begin{tabular}{|c|c|c|c|}
\hline & & PropIntelec & $B C$ \\
\hline \multirow[t]{2}{*}{ PropIntelec } & $\begin{array}{l}\text { Pearson Correlation } \\
\text { Sig. (2-tailed) }\end{array}$ & 1 & $\begin{array}{r}-, 822^{* *} \\
, 000\end{array}$ \\
\hline & $\mathrm{N}$ & 41 & 41 \\
\hline \multirow[t]{3}{*}{$B C$} & Pearson Correlation &,$- 822^{* *}$ & 1 \\
\hline & Sig. (2-tailed) & ,000 & \\
\hline & $\mathrm{N}$ & 41 & 41 \\
\hline
\end{tabular}

\begin{tabular}{|c|c|c|c|c|c|c|}
\hline & & IPin & DVA & DVAs & Exn & $\mathrm{Pl}$ \\
\hline \multirow[t]{2}{*}{ IPind } & $\begin{array}{l}\text { Pearson } \\
\text { Sig. (2-tailed) }\end{array}$ & 1 & ,000 & $\begin{array}{r}-219 \\
, 169\end{array}$ & $\begin{array}{l}251 \\
, 114\end{array}$ & ,40 \\
\hline & $\mathrm{N}$ & 41 & 41 & 41 & 41 & 41 \\
\hline \multirow[t]{3}{*}{ DVA } & Pearson & & 1 & 234 & & \\
\hline & Sig. (2-tailed) & 000 & & 141 & 081 & 35 \\
\hline & $\mathrm{N}$ & 41 & 41 & 41 & 41 & 41 \\
\hline \multirow[t]{3}{*}{ DVAserv } & Pearson & - & 234 & 1 & - & - \\
\hline & Sig. (2-tailed) & 169 & 141 & & 168 & 90 \\
\hline & $\mathrm{N}$ & 41 & 41 & 41 & 41 & 41 \\
\hline \multirow[t]{3}{*}{ ExpHT } & Pearson & 251 & - &,- 219 & 1 & - \\
\hline & Sig. (2-tailed) & 114 & 081 & , 168 & & 33 \\
\hline & $\mathrm{N}$ & 41 & 41 & 41 & 41 & 41 \\
\hline \multirow[t]{3}{*}{ PI_BC } & Pearson & - & - &,- 019 & - & 1 \\
\hline & Sig (2-tailed) & 403 & 352 & 906 & 338 & \\
\hline & & 41 & 41 & 41 & 41 & 41 \\
\hline
\end{tabular}


Tabela 4 - Indicadores

\begin{tabular}{|c|c|c|c|c|c|}
\hline & 1) & 2) & 3) & 4) & 5) \\
\hline & IP & DVA & UAserv & ExpHT & Intelec_BC \\
\hline Argentina & 0,22 & $-0,08$ & 0,00 & 0,07 & 0,26 \\
\hline Australia & 0,28 & $-0,02$ & $-0,03$ & $-0,10$ & 0,24 \\
\hline Austria & 0,33 & $-0,06$ & 0,02 & 0,02 & 0,30 \\
\hline Brazil & 0,24 & $-0,03$ & 0,02 & $-0,06$ & 0,23 \\
\hline Bulgaria & 0,34 & $-0,10$ & 0,02 & $-0,02$ & 0,29 \\
\hline Cambodia & 0,33 & $-0,24$ & 0,01 & 0,04 & 0,29 \\
\hline Canada & 0,25 & 0,01 & 0,02 & $-0,12$ & 0,20 \\
\hline Chile & 0,35 & $-0,06$ & $-0,01$ & 0,01 & 0,28 \\
\hline China & 0,26 & 0,01 & 0,01 & 0,24 & 0,05 \\
\hline Colombia & 0,26 & 0,01 & 0,00 & $-0,01$ & 0,28 \\
\hline Costa Rica & 0,28 & $-0,06$ & 0,09 & 0,33 & 0,29 \\
\hline Czech Rep. & 0,41 & $-0,15$ & $-0,02$ & 0,23 & 0,27 \\
\hline France & 0,29 & $-0,08$ & $-0,02$ & $-0,01$ & 0,47 \\
\hline Germany & 0,32 & $-0,11$ & 0,04 & 0,01 & 0,31 \\
\hline Hong Kong & 0,25 & 0,01 & 0,06 & 0,20 & 0,29 \\
\hline Hungary & 0,43 & $-0,19$ & $-0,01$ & 0,29 & 0,29 \\
\hline India & 0,32 & $-0,15$ & 0,06 & 0,06 & 0,35 \\
\hline Indonesia & 0,29 & 0,01 & $-0,01$ & 0,01 & 0,26 \\
\hline Ireland & 0,34 & $-0,05$ & 0,14 & $-0,12$ & 0,01 \\
\hline Israel & 0,27 & $-0,03$ & 0,03 & 0,03 & 0,29 \\
\hline Italy & 0,31 & $-0,09$ & 0,01 & $-0,03$ & 0,29 \\
\hline Japan & 0,33 & $-0,09$ & 0,00 & $-0,10$ & 0,61 \\
\hline Korea & 0,42 & $-0,19$ & 0,02 & 0,03 & 0,26 \\
\hline Malaysia & 0,37 & $-0,10$ & $-0,01$ & $-0,14$ & 0,26 \\
\hline Mexico & 0,28 & $-0,04$ & $-0,01$ & 0,00 & 0,30 \\
\hline Netherlands & 0,27 & 0,03 & 0,11 & 0,03 & 0,14 \\
\hline Philippines & 0,30 & 0,06 & 0,00 & 0,20 & 0,29 \\
\hline Poland & 0,38 & $-0,16$ & 0,02 & 0,19 & 0,27 \\
\hline Portugal & 0,30 & $-0,05$ & 0,01 & 0,02 & 0,29 \\
\hline Russia & 0,33 & 0,00 & 0,00 & $-0,06$ & 0,16 \\
\hline Singapore & 0,34 & 0,01 & 0,06 & $-0,18$ & 0,02 \\
\hline Slovak Rep. & 0,42 & $-0,15$ & $-0,02$ & 0,29 & 0,29 \\
\hline Slovenia & 0,36 & $-0,04$ & 0,02 & 0,04 & 0,29 \\
\hline South Africa & 0,29 & $-0,06$ & 0,00 & 0,09 & 0,26 \\
\hline Spain & 0,30 & $-0,08$ & 0,04 & $-0,09$ & 0,34 \\
\hline Sweden & 0,31 & $-0,03$ & 0,05 & $-0,02$ & 0,37 \\
\hline Switzerland & 0,29 & $-0,04$ & 0,05 & $-0,04$ & 0,34 \\
\hline Thailand & 0,36 & $-0,15$ & 0,00 & 0,05 & 0,24 \\
\hline Turkey & 0,30 & $-0,17$ & $-0,01$ & 0,15 & 0,33 \\
\hline U. Kingdom & 0,29 & $-0,05$ & 0,12 & $-0,15$ & 0,49 \\
\hline USA & 0,25 & $-0,04$ & 0,06 & $-0,13$ & 100 \\
\hline
\end{tabular}

* No cálculo dos clusters, atribuiu-se para o indicador 5 dos Estados Unidos o valor 1 (e não 100) por em função da disparidade do valor, o país ter ficado isolado dos demais grupos.
Tabela 5 - Indicadores agrupados

\begin{tabular}{|c|c|c|c|c|c|}
\hline Indicadores & 1) & 2) & 3) & 4) & 5) \\
\hline & IP & DVA & DVAserv & ExpHT & PIntelec_BC \\
\hline \multicolumn{6}{|l|}{ GRUPO 1} \\
\hline USA & 0,25 & $-0,04$ & 0,06 & $-0,13$ & $1 *$ \\
\hline UK & 0,29 & $-0,05$ & 0,12 & $-0,15$ & 0,49 \\
\hline Japan & 0,33 & $-0,09$ & 0 & $-0,1$ & 0,61 \\
\hline France & 0,29 & $-0,08$ & $-0,02$ & $-0,01$ & 0,47 \\
\hline Spain & 0,3 & $-0,08$ & 0,04 & $-0,09$ & 0,34 \\
\hline Austria & 0,33 & $-0,06$ & 0,02 & 0,02 & 0,3 \\
\hline Israel & 0,27 & $-0,03$ & 0,03 & 0,03 & 0,29 \\
\hline Sweden & 0,31 & $-0,03$ & 0,05 & $-0,02$ & 0,37 \\
\hline Switzerland & 0,29 & $-0,04$ & 0,05 & $-0,04$ & 0,34 \\
\hline Germany & 0,32 & $-0,11$ & 0,04 & 0,01 & 0,31 \\
\hline MÉDIA GRUPO & 0,3 & $-0,06$ & 0,04 & $-0,05$ & 0,45 \\
\hline MÉDIA AMOSTRA & 0,31 & $-0,07$ & 0,02 & 0,03 & 0,3 \\
\hline
\end{tabular}

\begin{tabular}{|lccccc|}
\hline \multicolumn{1}{c}{ GRUPO 2 } & & & & & \\
Italy & 0,31 & $-0,09$ & 0,01 & $-0,03$ & 0,29 \\
Portugal & 0,3 & $-0,05$ & 0,01 & 0,02 & 0,29 \\
Singapore & 0,34 & 0,01 & 0,06 & $-0,18$ & 0,02 \\
Ireland & 0,34 & $-0,05$ & 0,14 & $-0,12$ & 0,01 \\
Netherlands & 0,27 & 0,03 & 0,11 & 0,03 & 0,14 \\
India & 0,32 & $-0,15$ & 0,06 & 0,06 & 0,35 \\
Hong Kong & 0,25 & 0,01 & 0,06 & 0,2 & 0,29 \\
Costa Rica & 0,28 & $-0,06$ & 0,09 & 0,33 & 0,29 \\
\hline \multicolumn{1}{c}{ MÉDIA GRUPO } & 0,3 & $-\mathbf{0 , 0 4}$ & 0,07 & 0,04 & 0,21 \\
\hline MÉDIA AMOSTRA & $\mathbf{0 , 3 1}$ & $-0,07$ & $\mathbf{0 , 0 2}$ & $\mathbf{0 , 0 3}$ & 0,3 \\
\hline
\end{tabular}

GRUPO 3

\begin{tabular}{|lccccc|} 
Malaysia & 0,37 & $-0,1$ & $-0,01$ & $-0,14$ & 0,26 \\
Thailand & 0,36 & $-0,15$ & 0 & 0,05 & 0,24 \\
Korea & 0,42 & $-0,19$ & 0,02 & 0,03 & 0,26 \\
Rússia & 0,33 & 0 & 0 & $-0,06$ & 0,16 \\
Chile & 0,35 & $-0,06$ & $-0,01$ & 0,01 & 0,28 \\
Cambodia & 0,33 & $-0,24$ & 0,01 & 0,04 & 0,29 \\
Slovenia & 0,36 & $-0,04$ & 0,02 & 0,04 & 0,29 \\
Bulgaria & 0,34 & $-0,1$ & 0,02 & $-0,02$ & 0,29 \\
Czech Rep. & 0,41 & $-0,15$ & $-0,02$ & 0,23 & 0,27 \\
\hline Slovak Rep. & 0,42 & $-0,15$ & $-0,02$ & 0,29 & 0,29 \\
\hline Poland & 0,38 & $-0,16$ & 0,02 & 0,19 & 0,27 \\
\hline Hungary & 0,43 & $-0,19$ & $-0,01$ & 0,29 & 0,3 \\
\hline MÉDIA GRUPO & 0,38 & $-\mathbf{0 , 1 3}$ & 0 & 0,08 & 0,27 \\
\hline MÉDIA AMOSTRA & $\mathbf{0 , 3 1}$ & $-0,07$ & $\mathbf{0 , 0 2}$ & $\mathbf{0 , 0 3}$ & 0,3 \\
\hline
\end{tabular}

\begin{tabular}{|lccccc|}
\hline \multicolumn{1}{|c}{ GRUPO 4 } & & & & \\
China & 0,26 & 0,01 & 0,01 & 0,24 & 0,05 \\
Indonesia & 0,29 & 0,01 & $-0,01$ & 0,01 & 0,26 \\
\hline Philippines & 0,3 & 0,06 & 0 & 0,2 & 0,29 \\
\hline Turkey & 0,3 & $-0,17$ & $-0,01$ & 0,15 & 0,33 \\
\hline Colombia & 0,26 & 0,01 & 0 & $-0,01$ & 0,28 \\
\hline Mexico & 0,28 & $-0,04$ & $-0,01$ & 0 & 0,3 \\
\hline MÉDIA GRUPO & 0,28 & $-0,02$ & 0 & 0,1 & 0,25 \\
\hline MÉDIA AMOSTRA & $\mathbf{0 , 3 1}$ & $-0,07$ & $\mathbf{0 , 0 2}$ & $\mathbf{0 , 0 3}$ & 0,3 \\
\hline \multicolumn{1}{|c}{ GRUPO 5 } & & & & & \\
\hline Australia & 0,28 & $-0,02$ & $-0,03$ & $-0,1$ & 0,24 \\
\hline Brazil & 0,24 & $-0,03$ & 0,02 & $-0,06$ & 0,23 \\
\hline Canada & 0,25 & 0,01 & 0,02 & $-0,12$ & 0,2 \\
\hline Argentina & 0,22 & $-0,08$ & 0 & 0,07 & 0,26 \\
\hline South Africa & 0,29 & $-0,06$ & 0 & 0,09 & 0,26 \\
\hline MÉDIA GRUPO & 0,26 & $-\mathbf{0 , 0 4}$ & 0 & $-0,02$ & 0,24 \\
\hline MÉDIA AMOSTRA & $\mathbf{0 , 3 1}$ & $-0,07$ & $\mathbf{0 , 0 2}$ & $\mathbf{0 , 0 3}$ & 0,3 \\
\hline
\end{tabular}

